Jussara Maria Rosa Mendes ${ }^{1}$

Dolores Sanches Wünsch ${ }^{2}$

\section{Elementos para uma nova cultura em segurança e saúde no trabalho}

\author{
Elements for a new culture in labor safety and health
}

\footnotetext{
${ }^{1}$ Assistente social. Doutora em Serviço Social pela Pontifícia Universidade Católica de São Paulo. Diretora da Faculdade de Serviço Social da Pontifícia Universidade Católica do Rio Grande do Sul. Coordenadora do Núcleo de Estudos e Pesquisa em Saúde e Trabalho do Programa de Pós-Graduação em Serviço Social da Pontifícia Universidade Católica do Rio Grande do Sul, Brasil.

${ }^{2}$ Assistente social. Doutora em Serviço Social pela Pontifícia Universidade Católica de São Paulo. Professora da Faculdade de Serviço Social da Pontifícia Universidade Católica do Rio Grande do Sul. Pesquisadora do Núcleo de Estudos e Pesquisa em Saúde e Trabalho do Programa de Pós-Graduação em Serviço Social da Pontifícia Universidade Católica do Rio Grande do Sul, Brasil.
}

\section{Resumo}

Este artigo propõe-se a discutir o cenário contemporâneo das relações entre saúde e trabalho, apontando alguns elementos que possam contribuir para o debate sobre o tema, na perspectiva de alcançar uma nova cultura em segurança e saúde no trabalho. Evidencia-se que a predominância do viés prevencionista nesta área, que se consolidou ao longo dos anos, é resultado de um modelo hegemônico centrado no biológico e no indivíduo. A construção de práticas voltadas para a atenção à saúde do trabalhador exige uma abordagem interdisciplinar e passa pela apreensão de novos referenciais em saúde e trabalho, compreendendo-os como um processo dinâmico e social.

Palavras-chaves: acidente de trabalho, segurança no trabalho, saúde do trabalhador.

\begin{abstract}
This article discusses the contemporary scenario of the relationship between health and labor, pointing out some elements that may contribute to the debate on this topic from the perspective of a new culture for labor safety and health. It shows that the predominance of the view based on prevention, that has been consolidated over time, derives from a hegemonic model focused on the biological and individual dimension. The construction of practices oriented to the workers' health requires an interdisciplinary approach and involves the apprehension of new referents in health and labor understanding them as a dynamic and social process.
\end{abstract}

Keywords: labor accident, labor safety, workers' health. 


\section{Introdução}

O conhecimento produzido nas últimas duas décadas sobre a prevenção de acidentes de trabalho vem desafiando os profissionais da área de saúde e segurança do trabalho a repensar os modelos de gestão e de intervenção centrada na lógica da prevenção individual. Exige fundamentalmente a compreensão das transformações em curso, à luz das mudanças do mundo do trabalho, para que a prevenção seja pensada na perspectiva das modificações das condições e relações de trabalho. Constata-se na atualidade não apenas o surgimento e o crescimento de novas patologias relacionadas ao trabalho, como também a persistência de acidentes típicos, os quais têm seus limites na organização do trabalho. A saúde e o trabalho estão permeados pelas grandes transformações societárias e suas contradições contemporâneas, relacionadas fundamentalmente aos processos de gestão e organização do trabalho, viabilizados em especial pelas novas tecnologias, impactando na saúde dos trabalhadores. Sistemas produtivos antigos e ultrapassados coexistem com os processos modernos e tecnologicamente superiores. É neste contexto que os agravos relacionados ao trabalho revestem-se de novos significados e determinações ao mesmo tempo em que indicam a necessidade de superar problemas antigos.

Este artigo tem como objetivo refletir sobre o acidente de trabalho e as doenças a ele relacionadas em meio ao contexto atual, bem como contribuir para a compreensão desta temática, considerando a abrangência das ações de saúde e a concepção ampla do processo de saúde-doença e de seus determinantes. Entende-se a prevenção não como uma ação unívoca, mas como resultado de uma política de gestão em saúde do trabalhador. Este enfoque é mais amplo e abrangente, uma vez que busca identificar e enfrentar os macrode- terminantes do processo saúde-doença na perspectiva de transformá-los na direção da saúde (BUSS, 2000).

A perspectiva aqui referida deve ser pensada com base na premissa de que a saúde do trabalhador sofre forte impacto do capitalismo contemporâneo, em que a produtividade, a competitividade e a flexibilidade se sobrepõem aos aspectos humanos e sociais. Portanto, é preciso extrapolar os "muros" da empresa e construir estratégias que articulem a participação e o envolvimento de diferentes instâncias tripartites, compostas por trabalhadores, empresários e governo, para gerar um desenvolvimento não apenas sustentável, mas socialmente capaz de enfrentar as conseqüências do atual modelo econômico. Aponta-se também como estratégia a articulação das ações no âmbito do trabalho industrial com a Política Nacional de Segurança e Saúde do Trabalhador e com as diretrizes nela contidas, visando à integralidade das ações na área.

A relevância da discussão sobre o acidente de trabalho e o processo saúdedoença e, conseqüentemente, suas repercussões sobre a vida do trabalhador vêm se ampliando, bem como o impacto social que estes agravos produzem. Apesar de avanços científicos e tecnológicos em diferentes esferas da sociedade, que trazem resultados benéficos para a saúde da população e dos trabalhadores em geral, ocorre, contraditoriamente, uma expressiva elevação da morbi-mortalidade nesta área. Revela-se, portanto, que é preciso avançar na construção de uma nova cultura ${ }^{3}$ em saúde do trabalhador. Essa cultura representa o estabelecimento de pactos, princípios e valores que devem nortear práticas e condutas que atendam novas e antigas demandas da área. o modo de viver, de pensar e de sentir a realidade por parte de uma civilização e, por outro lado, é concebida como projeto de formação do indivíduo, como ideal educativo a ser transmitido para as novas gerações (VIEIRA, 1999).

\section{Concepções e cenário do acidente de trabalho e do processo de saúde-doença}

As determinações que incidem sobre a saúde do trabalhador na contemporaneidade estão fundamentalmente relacionadas às novas modalidades de trabalho e aos processos mais dinâmicos de produção implementados pelas inovações tecnológicas e pelas atuais formas de organização do trabalho. As profundas transformações que vêm alterando a economia, a política e a cultura na sociedade por meio da reestruturação produtiva e do incremento da globalização, entre outros motivos, implicam também mudanças nas formas de gestão do trabalho que engendram a precariedade e 
a fragilidade das questões que envolvem a relação entre saúde e trabalho e as condições de vida dos trabalhadores.

Do ponto de vista científico, a saúde e a doença referem-se a fenômenos vitais, sendo formas pelas quais a vida se manifesta. As experiências dos sujeitos e as idéias dominantes do meio social são determinantes no processo de construção social da doença e da saúde. Desse modo, em um contexto de valorização da capacidade produtiva das pessoas, estar doente pode significar, para o trabalhador, ser indesejável ou socialmente desvalorizado.

Assim, para se abordar a questão do acidente e da doença relacionada ${ }^{4}$ com o trabalho, é imprescindível identificar as relações que se estabelecem no âmbito da saúde do trabalhador, compreendendo-a como embasada na seguinte premissa:

Os trabalhadores apresentam um viver, adoecer e morrer compartilhado com o conjunto da população, em um dado tempo, lugar e inserção social, mas que é também específico, resultante de sua inserção em um processo de trabalho particular. (DIAS, 1996, p. 28)

Nesse sentido, a saúde do trabalhador pressupõe uma interface entre diferentes alternativas de intervenção que contemplem as diversas formas de determinação do processo de saúde-doença dos trabalhadores. As alterações introduzidas na Carta Constitucional brasileira de 05/10/1988 no seu artigo 196 não deixam dúvidas quanto ao fato de que, desde então, a saúde passou a ser entendida como direito de cidadania, devendo ser garantida pelo Estado a partir de suas políticas sociais e econômicas, bem como por meio de outras medidas que possibilitem reduzir os riscos e os agravos e, ainda, que assegurem o acesso aos serviços através do Sistema Único de Saúde - SUS (DIAS, 1996).

Assim, é necessário pensar a saúde do trabalhador desde a sua organização na sociedade e no trabalho, compreendendo-se essa realidade sob uma perspectiva de sujeitos coletivos, conhecendo-os e reconhecendo-os historicamente.

Em uma análise transversal dessas mudanças, nos últimos 30 anos, transparece, claramente, o direcionamento para uma nova hierarquização do setor, na qual o homem passa a assumir a instância de sujeito das ações, transcendendo a sua condição anterior de objeto no processo de atenção à sua saúde. No Brasil, os marcos fundamentais referentes a tais mudanças foram a realização da VIII e da IX Conferências Nacionais de Saúde (1986 e 1992, respectivamente) e a inserção do conceito de saúde na Constituição Federal, eventos esses que evidenciaram uma nova relação do homem com seu meio social. A saúde passou a ser percebida não mais apenas por sua ausência, mas como "[...] resultante das condições de alimentação, educação, salário, meio ambiente, trabalho, transporte, emprego, lazer e liberdade, acesso à propriedade privada da terra e acesso aos serviços de Saúde” (BRASIL, 1988). Os conceitos que definiam a Medicina do Trabalho e a Saúde Ocupacional, utilizados até então, não contemplavam essa complexidade e também as necessidades da área naquele momento; daí a importância de se apreender esse processo em sua totalidade, buscando-se somar esforços e conhecimentos para se intervir nessa realidade.

Tradicionalmente, a atenção prestada a essa área se voltava para o trabalho formal e, dentro deste, ao trabalho industrial. Porém, a realidade de hoje difere, em muito, desse paradigma de trabalho, o que, sem dúvida, muda a forma de se compreender a questão, exigindo transformações radicais na maneira de se conceber e de se enfrentar os problemas daí decorrentes. A análise sob uma perspectiva evolutiva e conceitual indica que, na Medicina do Trabalho, o enfoque principal da determinação do processo de saúde-doença é individual, biologicista, como demonstra a sistematização realizada por Mendes e Oliveira (1995), no Quadro 1.
${ }^{4}$ Este tema foi abordado no verbete "acidente de trabalho" de Trabalho e tecnologia: dicionário crítico (MENDES, 2002).

Quadro 1 Desenvolvimento conceitual da saúde do trabalhador

\begin{tabular}{|l|l|l|l|l|l|l|}
\hline $\begin{array}{c}\text { Determinantes do } \\
\text { processo }\end{array}$ & \multicolumn{1}{|c|}{ ação principal } & caráter principal & ator principal & \multicolumn{1}{c|}{ cenário } & papel do usuário & \multicolumn{1}{c|}{ campo da saúde } \\
\hline Biológico & tratamento da doença & técnico & médico & hospital & $\begin{array}{l}\text { usuário é objeto } \\
\text { da ação }\end{array}$ & Medicina do Trabalho \\
\hline Ambiental & prevenção da doença & técnico & equipe & ambulatório & $\begin{array}{l}\text { usuário e ambiente } \\
\text { são objetos }\end{array}$ & Saúde Ocupacional \\
\hline Social & promoção da saúde & técnico e político & cidadão & sociedade & sujeito & Saúde do Trabalhador \\
\hline
\end{tabular}

Fonte: Mendes e Oliveira (1995). 
A concepção atual de saúde do trabalhador entende o social como determinante das condições de saúde e, sem negar que os doentes devam ser tratados e que seja necessário prevenir novas doenças, privilegia ações de promoção da saúde. Entende que as múltiplas causas dos acidentes e das doenças do trabalho têm uma hierarquia entre si, não sendo neutras e iguais, havendo algumas causas que determinam outras (MENDES \& OLIVEIRA, 1995). Diferentemente das visões dicotomizadas anteriores, propugna-se que os programas de saúde incluam a proteção, a recuperação e a promoção da saúde do trabalhador de forma integrada e que sejam dirigidos não só aos trabalhadores que sofrem, adoecem ou se acidentam, mas também ao conjunto dos trabalhadores (DIAS, 1996). Essas ações devem ser redirecionadas para se alcançar as múltiplas mudanças que ocorrem nos processos de trabalho, sendo realizadas através de uma abordagem transdisciplinar e intersetorial e, ainda, com a imprescindível participação dos trabalhadores.

A dinâmica da produção, as condições de trabalho e o modo de vida continuam sendo fontes importantes para que se compreenda o processo de saúde, adoecimento e morte da população brasileira. Portanto, falar do processo de saúde-doença é buscar compreender esse binômio que evidencia sentimentos, não menos contraditórios, de dor e felicidade por se estar diante das questões da vida e da morte, da doença e da saúde das pessoas. Evidencia-se, assim, que a doença, a saúde e a morte não se reduzem a evidências "orgânicas", "naturais", "objetivas"; elas estão intimamente inter-relacionadas com características de cada sociedade. Expõem pontos reveladores, como o fato de a doença ser socialmente construída e de o doente ser um personagem social. Transparece, pois, que a compreensão do processo de acidente e adoecimento transcende a aceitação de sua multicausalidade, identificando-se seu fator determinante no social. Santos (1985), buscando ampliar a percepção do processo de trabalho para além do ambiente fabril, considera a compreensão da doença como

[...] uma dinâmica que abrange não só a produção, consumo e reposição do trabalhador diretamente envolvido no processo de trabalho, mas também, de forma ampla, a produção da população que compõe a classe trabalhadora, que expressa, no seu corpo, a face social do ser. (p. 15)
Dessa forma, fica evidente que o binômio saúde-doença pressupõe a articulação entre as diferentes interfaces sociais e que ele depende do modo de viver, da qualidade de vida e do acesso que os indivíduos têm a bens e serviços (DIAS, 1996). Ao refletirmos sobre saúde, acidente, doença e trabalho na vida dos indivíduos e da coletividade, fica cada vez mais difícil falarmos de um mundo do trabalho que pertença, unicamente, à esfera da fábrica e de um outro mundo externo ao trabalho, pertencente à esfera da rua.

Verificamos a existência de uma complexa interação entre aspectos físicos, psicológicos e sociais relevantes para a compreensão daquilo que seja a história humana. Eles não deixam dúvidas quanto ao fato de que a saúde e o adoecimento, o viver e o morrer dos indivíduos estão diretamente relacionados a questões que ultrapassam análises de sua causalidade e multicausalidade.

Nessa perspectiva, a matriz da estrutura de prevenção e proteção da saúde no trabalho passa a se constituir mais como uma forma de controle da força de trabalho do que como atenção à saúde: há todo um sistema estruturado para se darem rápidas e competentes respostas às necessidades do sistema econômico a qualquer custo, tendo como base a equação denunciada por Thébàud-Mony (1997): crescimento econômico = progresso social, sustentáculo das regulações sociais adotadas. Dessa maneira, a saúde dos trabalhadores é resultante de uma articulação política, econômica e monetária, na qual as desigualdades sociais diante das doenças e da morte são os principais elementos reveladores dessa dinâmica, estruturada pelas relações sociais de produção.

Concebe-se, portanto, que o conceito do que é o acidente e a doença advinda do trabalho é um dos frutos dessa construção social. Nessa dinâmica, encontra-se o conceito de "risco aceitável", baseado na inter-relação entre o diagnóstico pericial e a determinação das normas que enquadram os riscos nos limites do medicamente aceitável. Seus artifícios são a desqualificação (o desnivelamento da qualificação) dos trabalhadores ditos de "fora do quadro, exteriores, ajudantes" e a redução do tempo de trabalho, com rebaixamentos salariais legalmente permitidos quando se trata de trabalho em tempo parcial. 
Por outro lado, o próprio conceito legal de acidente de trabalho, em que se equipara doença profissional e doença do trabalho, constante da Lei n. 8213 (BRASIL, 1997), que dispõe sobre os Planos de Benefícios da Previdência Social, tem se demonstrado contraditório na sua aplicabilidade. Além disso, devido ao quadro de violência urbana, notadamente a relacionada ao trânsito e aos assaltos, assumem particular valor os eventos ocorridos no percurso da residência para o trabalho e vice-versa.

Nos termos das Ciências Sociais, considera-se acidente de trabalho todo acidente que ocorra no transcurso da atividade do homem na transformação da natureza, no processo de criação de mercadorias com fins econômicos, remunerado ou não (ALBORNOZ, 1994), excluindo-se, portanto, apenas as atividades com caráter de hobby ou lazer, por exemplo.

A legislação brasileira encontra-se embasada nessa dicotomia entre fatores humanos e ambiente de trabalho. Os riscos, os atos inseguros, o risco aceitável, os limites suportáveis pelo trabalhador, em geral, são caracterizados dentro das empresas e estão tensionados pela necessidade de se reduzir o número de acidentes a qualquer custo.

A legislação em vigor relativa ao acidente de trabalho encontra-se sob a égide da Constituição da República Federativa do Brasil, promulgada em 5 de outubro de 1988. Consta, em seu artigo $7^{\circ}$, que estão contemplados os direitos dos trabalhadores urbanos e rurais, além de outros benefícios que visem à melhoria de sua condição social. Nesse artigo se destacam os seguintes incisos:

\section{$[\ldots]$}

XXII - redução dos riscos inerentes ao trabalho, por meio de normas de saúde, higiene e segurança;

XXVIII - seguro contra acidentes de trabalho, a cargo do empregador, sem excluir a indenização a que está obrigado, quando incorrer em dolo ou culpa;

XXXIII - proibição de trabalho noturno, perigoso ou insalubre aos menores de dezoito anos e de qualquer trabalho a menores de quatorze anos, salvo na condição de aprendiz;

XXXIV - igualdade de direitos entre o trabalhador com vínculo empregatício permanente e o trabalhador avulso; $[\ldots]$

Assim, a redução dos riscos inerentes ao trabalho e o seguro contra acidentes de trabalho são direitos de todos os trabalhadores. Sem exclusão do direito à indenização a que fazem jus quando ocorre dolo ou culpa, todos os trabalhadores teriam direito constitucional à cobertura por um seguro contra acidentes de trabalho, independentemente da sua forma de inserção no mercado de trabalho.

O reconhecimento legal e, conseqüentemente, o direito a ele relacionado ocorrem a partir da notificação oficial do acidente de trabalho e cabe à Previdência Social a caracterização do acidente de trabalho de forma administrativa e o estabelecimento do nexo entre o trabalho exercido e o acidente. Tecnicamente, isso é feito através da perícia médica, que determina o nexo de causa e efeito entre o acidente e a lesão, a doença e o trabalho ou entre a causa mortis e o acidente. Entretanto, há um crescimento significativo do número de trabalhadores afastados do trabalho por incapacidade, sendo que, contraditoriamente, o benefício por acidente de trabalho representa menos de $20 \%$ desta parcela (BRASIL, 2005).

Os dados oficiais disponíveis no Brasil não revelam a realidade do acidente e da doença do trabalho, primeiro pelo fato de que o conceito de acidente de trabalho, para fins de enquadramento no Seguro de Acidente do Trabalho e, secundariamente, para fins de inclusão nas estatísticas oficiais, abrange, exclusivamente, alguns trabalhadores urbanos (o empregado - exceto o doméstico -, o trabalhador avulso, o segurado especial e o médico residente) e os trabalhadores rurais empregados ou membros de unidade de economia familiar. Excluem-se completamente, portanto, no âmbito do mercado formal, todos os trabalhadores domésticos, os autônomos e todos os servidores públicos civis e militares (municipais, estaduais e federais), além de todos os acidentes de trabalho que ocorram com trabalhadores não registrados e os do mercado informal de trabalho. Neste sentido, os números divulgados pela Organização Internacional do Trabalho (OIT) são alarmantes e representam apenas uma parcela desta realidade. A estimativa da entidade é de que, no mundo todo, os acidentes e as doenças do trabalho matem, por ano, cerca de 2 milhões de trabalhadores. As doenças relacionadas ao trabalho respondem por 1,6 milhão de mortes; os acidentes de trabalho, por 360 mil mortes. O número de mortes causadas por acidentes e doenças relacionadas ao trabalho ultrapassa aquele causado por epidemias como 
${ }^{5}$ Pode-se mencionar, neste sentido, a experiência do Núcleo de Estudos em Saúde e Trabalho (NEST), da Faculdade de Serviço Social da Pontifícia Universidade Católica do Rio Grande do Sul, cujos pesquisadores têm buscado aliar descrições possíveis do adoecimento às notificações dos sistemas públicos existentes, além dos procedimentos metodológicos que permitam a articulação entre o cotidiano de vida e de trabalho e a ocorrência dos agravos à saúde do trabalhador. O Núcleo vem utilizando como fontes de pesquisa a validação das informações contidas no banco de dados da Delegacia Regiona do Trabalho (DRT/RS), através das Comunicações de Acidentes de Trabalho (CATs) que a Previdência Social informa àquela instância regional do trabalho, e as referidas nos sistemas do SUS/RS, a saber, o RINA (Relatório Individual de Notificação de Agravos) e o RINAV (Relatório Individual de Notificação de Acidente e Violência). a AIDS. No Brasil, segundo o Ministério da Previdência Social, em 2005, foram registrados 492 mil casos de acidentes e doenças relacionadas ao trabalho, com 2.708 mortes de trabalhadores (BRASIL, 2005). Esses dados, no entanto, são parciais e as justificativas, já referidas anteriormente, reafirmam as dificuldades com as quais nos deparamos ao tratar dos acidentes de trabalho no Brasil.

Como pode ser demonstrado, em termos da legislação previdenciária, no que tange ao seguro contra acidente do trabalho, ainda é grande a parcela de trabalhadores do setor formal que são excluídos de sua cobertura face à ausência de efetiva caracterização do adoecimento relacionado ao trabalho, seja pelo empregador, seja pela previdência social. Por conseguinte, muitas infortunísticas referentes ao trabalho não são levadas ao Ministério do Trabalho e, daí, aos órgãos internacionais. Relacionando-se, ainda, o perfil do tipo de trabalhador do mercado formal que tem acesso ao seguro acidentário com o tamanho de nosso mercado informal de trabalho, temse a exata idéia do quanto trabalhadores estão fora das estatísticas oficiais e sem proteção social. Em relação a essa discussão, ganha relevância o papel das pesquisas sobre acidente, doença e morte no trabalho ${ }^{5}$. Através da pesquisa é possível desvendar a dinâmica que envolve o adoecimento e $\mathrm{o}$ acidente de trabalho identificando os elementos consensuais e as divergências, a relação entre os processos de trabalho, as determinações sociais e a manifestação de doenças do trabalho e profissionais, a exposição ocupacional a agentes nocivos para a saúde do trabalhador e seus agravos latentes e residuais.

E, por último, não poderíamos deixar de apontar o que Dwyer (1991) refere como intrínseca correspondência entre a história da saúde no trabalho e as histórias que se inscrevem na evolução do conhecimento de processos sociais de gestão dos riscos no trabalho. A construção da paz social en-

\section{Da prevenção do acidente de trabalho à saúde do trabalhador}

O contexto atual não só altera as múltiplas determinações da saúde do trabalhador, como exige um redimensionamento dos conhecimentos e das ações nesta área que contemple as diferentes manifestações que emergem da relação do trabalho versus saúde-doença. A visão prevencionista tre patronato e movimento sindical dá-se em torno de questões referentes à saúde e à segurança através da prevenção alcançada pela formação profissional. Porém, a ruptura desta paz social ocorre por ocasião de grandes catástrofes sanitárias, indicando a chegada de um momento de acidentes de grandes proporções, com impactos coletivos na saúde e no meio ambiente. Tal situação revela o choque social dos acidentes quando, pela sua gravidade, provocam importantes perturbações nos planos emocional, psíquico e psicossocial daqueles diretamente envolvidos, como especialistas, técnicos, mas principalmente a população em geral, através da proximidade que a mídia pode oferecer do evento. Para Llory (1999), esses episódios são o retorno à dimensão oculta ou ocultada da construção social dos agravos relacionados ao trabalho, a desforra da realidade global sobre a visão reducionista da ciência especializada.

Se reconhecermos que a saúde e a doença se definem como um processo dinâmico, expresso no corpo, no trabalho, nas condições de vida, nas dores, no prazer e no sofrimento, enfim, em tudo que compõe uma história singular, mas também coletiva, pela influência das múltiplas lógicas inscritas nesse processo, estaremos caminhando para uma concepção ampliada de saúde do trabalhador (MENDES, 2003).

O cenário, portanto, compõe-se de diferentes interfaces, fruto de construções sociais, históricas e contemporâneas, entrelaçando concepções e aspectos legais, estruturais e conjunturais. Esse sistema está fundado na prevenção e na reparação de danos à saúde, focalizado no indivíduo e, secundariamente, na organização do trabalho. Ao se constatar que as relações de produção vêm apresentando outras configurações e impondo demandas diferenciadas, redobram-se as exigências e os cuidados na área da saúde do trabalhador, elevando-se a um novo patamar as ações e estratégias dos profissionais nela inseridos.

que centra nos trabalhadores os cuidados com os riscos a que estão expostos revelase deficitária e acaba ocultando as manifestações decorrentes da inserção produtiva e social destes trabalhadores. Nesse sentido, não promove a saúde nem o enfrentamento dos diferentes condicionantes. Prevalece 
uma ação normatizadora da legislação vigente em detrimento das reais possibilidades de formular proposições conjuntas que atendam as necessidades oriundas da vida no trabalho, pois a concepção de saúde do trabalhador e seus aspectos relacionados à prevenção e à proteção ocupacional devem reconhecer o processo de doença-trabalho dentro e fora do âmbito produtivo e, fundamentalmente, como as diferentes expressões de agravo à saúde se manifestam em diferentes épocas e espaços profissionais.

Destaca-se que uma questão sempre atual diz respeito à concepção adotada quanto às causas dos acidentes de trabalho. A mais freqüente indica que os acidentes de trabalho são resultantes dos chamados atos inseguros praticados pelo próprio trabalhador. Contudo, sabemos que mesmo aqueles acidentes que ocorrem pelo descuido do trabalhador muitas vezes são condicionados por diferentes determinantes, tais como o cansaço provocado pelas horas extras, estafa crônica, horas não dormidas, alimentação e transporte deficientes, precárias condições ambientais, manuseio de máquinas e equipamentos que requeiram atenção redobrada, intensificação do ritmo de trabalho, exigências de um trabalhador polivalente e más condições de vida e de trabalho, entre outras causas. A lógica apresentada tende a imputar a culpa ao trabalhador:

[...] vai desde teorias da culpa, em que é enfatizada a imperícia do trabalhador; à acidentabilidade, que supõe a existência de trabalhadores acidentáveis; à predisposição aos acidentes, em função de características individuais, e à dicotomia entre os fatores humanos e o ambiente do trabalho. (MACHADO \& MINAYO-GOMES, 1995, p. 118).

Historicamente, o trabalhador se tornou objeto de ações que centram nele a responsabilidade de evitar a iminência de dano ou risco à sua saúde, tendendo, ao mesmo tempo, a responsabilizá-lo em caso de acidente de trabalho em detrimento das condições de trabalho, caracterizando, portanto, o acidente como conseqüência de "ato inseguro”. Segundo Wünsch (2005), essa visão, que parece ter se consolidado em meio aos profissionais da área, desencadeou dois processos opostos e linearmente construídos:

a) conceber o acidente de trabalho como produto da conduta do trabalhador no seu ambiente laboral; este é entendido como resultante de causa endógena e in- dividualizada por parte do acidentado. A ação tende a "educar" o indivíduo para se prevenir;

b) centrar o foco no indivíduo contribui para um distanciamento da percepção da saúde do trabalhador como algo implicado também com as condições de vida - alimentação, habitação, remuneração, entre outros - e com a organização do trabalho - incluindo todos os componentes do processo de trabalho, como a força de trabalho, os desgastes físico, psíquico e social, a matéria-prima (muitas vezes insalubre, de manuseio penoso e pesado, tóxica etc.), os instrumentos de trabalho e os riscos ao operacionalizá-los.

Para melhor compreender-se esse segundo processo, é importante a formulação de Laurell e Noriega (1989), que utilizam a categoria "carga de trabalho" em detrimento do conceito de risco. Essa categoria tem contribuído para determinar o objeto da saúde do trabalhador como o estudo do processo de saúde-doença dos grupos humanos sob a ótica do trabalho. Nessa perspectiva de análise, a carga de trabalho é definida pelos autores como abarcando tanto as condições físicas, químicas e mecânicas quanto as fisiológicas, as quais interatuam dinamicamente entre si e no corpo do trabalhador (MINAYOGOMEZ \& THEDIM-COSTA, 1997).

Em relação a essa análise, constata-se que os meios de proteção à saúde têm se dado de forma externa ao trabalhador, fazendo com que ele não seja sujeito do processo, como bem coloca Possas:

As condições de trabalho e saúde estão estreitamente associadas às condições em que se realiza o processo produtivo e são por elas determinadas. O grau de importância que será dado ao problema da saúde, da doença ocupacional e do acidente do trabalho é determinado pela posição e pela importância relativa dos trabalhadores como parte deste processo. (POSSAS, 1989, p. 118)

Nas situações em que se pode reconhecer o dano à saúde, pouco se tem olhado para o "controle" da carga de trabalho; além disso, a prevenção e a eliminação dos riscos não têm levado em conta a progressividade do desgaste humano lentamente acumulado, que não é só físico. Assim, pode-se dizer que, em algumas situações de agravos à saúde, ocorreram avanços na identificação, na caracterização, no diagnóstico e no tratamento dos acidentes e das doenças, porém tem-se uma outra face 
${ }^{6} \mathrm{O}$ conjunto de proposições se encontra no documento "Resoluções da $3^{\text {a }}$ Conferência Nacional da Saúde do Trabalhador", versão de 24 de abril de 2006, disponível no site: http://www.saude.gov.br dessa realidade, que é o passivo de trabalhadores colocados para fora do meio produtivo, face à perda da capacidade laboral, e estigmatizados pelo mercado de trabalho. Esta realidade demarca aos empregadores a necessidade de reverem não apenas as condições ambientais e organizacionais do trabalho, mas também seus modelos de gestão da saúde para o trabalhador.

A noção de risco indenizável da saúde, através de reparação pecuniária do acidente de trabalho e/ou doença legalmente caracterizada, teve grande impacto no desenvolvimento dos seguros sociais, contribuindo para que estes se vinculassem à idéia de reparação, ou seja, pagando-se pelas conseqüências sem olhar as causas.

Como retrata Pezerat (2000), a implantação dos seguros permitiu pagar pelos estragos sem recriminar os erros, sendo estes suplantados pelo conceito de risco sem questionar a responsabilidade legal, uma vez que os trabalhadores estavam segurados.

Em meio a essa cultura, em que prevalece a individualização da prevenção, a visão monetarista do dano em detrimento do entendimento do que é saúde, parece-nos oportuno trazer outros elementos que vêm repercutindo diretamente nas condições de trabalho e de vida do trabalhador. Estes dizem respeito à questão da saúde mental no trabalho.

Autores como Dejours (1988) e Seligman (1990) chamam a atenção para os aspectos geradores de risco à saúde dos trabalhadores, fundamentalmente relacionados ao processo de organização do trabalho. Para Dejours (1988), o sofrimento no trabalho se relaciona à insatisfação com a tarefa realizada e seu conteúdo significativo e também ao conteúdo ergonômico do trabalho. A adaptação do homem ao trabalho, seja ela física ou mental, vem merecendo diferentes estudos por parte da ergonomia, que se preocupa com os meios e as condições de execução do trabalho. As melhorias dessas condições dizem respeito ao grau de participação, autonomia e organização dos envolvidos (OLIVEIRA, 2002). Entretanto, segundo este mesmo autor, é importante diferenciar o trabalho real e o trabalho prescrito, ou seja, o trabalho efetivamente realizado, o real, depende dos meios fornecidos para realizá-lo e das condições físicas e mentais do trabalhador. Neste sentido, o resultado do trabalho depende de vários fatores que envolvem o trabalhador, a empresa, as condições de saúde e trabalho. Decorre desse contexto também a necessidade do reconhecimento do trabalho real, pelos diferentes níveis de relações de trabalho e sociais do trabalhador, como fator subjetivo de satisfação e saúde mental no trabalho.

Em estudo realizado por Seligman (1990) sobre condições de trabalho e vida dos trabalhadores vinculadas à saúde mental destes, a autora chama a atenção para as condições que são derivadas também das características da organização do trabalho. Destaca os seguintes fatores de riscos para a saúde mental: jornada prolongada; trabalhos em turnos alternantes; ritmo acelerado e exigências referidas ao mesmo; tempo de descanso insuficiente; hierarquização rígida; sistemas de controle do desempenho na produção; sistema insatisfatório de segurança do trabalho; rotatividade de pessoal; desinformação; desvios de função e acúmulo de funções. Situa também os riscos físicos, ambientais e químicos, bem como as relações interpessoais conflituosas dentro da empresa, principalmente em relação às chefias, como geradoras de mágoa e insatisfação. O mesmo estudo traz outras questões relacionadas às condições de vida como fatores principais causadores de tensão e a perdas relacionadas à migração e habitação em condições insatisfatórias, entre outras.

Conclui-se que a compreensão da forma de organização do trabalho, imbricada com as necessidades advindas das condições de vida do trabalhador, é central para a (re)formulação de uma proposta de gestão em saúde do trabalhador nas empresas que venha a ser articulada com a política específica para esta área.

A $3^{\mathrm{a}}$ Conferência Nacional da Saúde do Trabalhador, realizada em dezembro de 2005, referendou esta orientação política. Uma das resoluções aprovadas ${ }^{6}$ aponta a necessidade de o Estado promover ações de integralidade no desenvolvimento de políticas universais, intersetoriais e integradas - saúde, trabalho e emprego e previdência social -, contemplando ações preventivas, de promoção da saúde, de vigilância (epidemiológica, sanitária, ambiental e de saúde do trabalhador), curativas e de reabilitação que garantam o acesso do trabalhador a um atendimento humanizado, cuja consecução esteja assegurada nas três esferas de governo - federal, estadual e municipal. Para tal, as ações devem contar com a participação do empregador na promoção de 
condições salubres de trabalho e na eliminação de riscos à saúde do trabalhador.

O documento da conferência enfatiza que a discussão de segurança e saúde do trabalhador, incluindo-se a Política Nacional de Segurança e Saúde do Trabalhador, deve estar pautada nos conceitos de desenvolvimento sustentável e de responsabilidade social, com o desenvolvimento de subsídios conceituais à introdução de políticas de saúde do trabalhador nas políticas de desenvolvimento econômico e social. Essas são propostas que têm como eixo a redefinição do papel das empresas na participação na política pública de saúde e de sua responsabilidade na promoção da saúde.

Destaca-se ainda uma terceira proposta, a qual objetiva transformar os Serviços Especializados em Engenharia de Segurança e em Medicina do Trabalho (SESMT), com base na Norma Regulamentadora NR-4 do Ministério do Trabalho e Emprego, em serviços especializados de segurança e saúde no trabalho, contando com a participação efetiva das empresas e dos órgãos públicos e privados na melhoria das condições laborais, de forma articulada com os profissionais das áreas de saúde, segurança e meio ambiente. Na perspectiva das formulações expressas neste artigo, não se trata de uma mera mudança de nomenclatura, mas, sim, de uma nova concepção em saúde do trabalhador. Visa-se a uma concepção que supere a prevalência de uma visão biologista e curativa da saúde, restrita à Medicina, passando a ser resultado da interdisciplinaridade no conhecimento e na ação, bem como a uma concepção na qual o trabalhador passe a ser sujeito do processo.

Trabalhar na perspectiva da saúde e não da doença ou do dano é possível desde que os diferentes atores envolvidos tenham papel valorizado na promoção da saúde, independentemente do seu grau de inser- ção no processo produtivo ou hierárquico. Significa reafirmar que todos envolvidos neste processo devem se reconhecer e estabelecer relações de horizontalidade na construção de proposições que visem a vigiar e proteger a saúde. Deve-se igualmente garantir o estabelecimento de medidas efetivas na proteção dos trabalhadores incorporadas à política gerencial e de desenvolvimento das empresas e articuladas com a Política Nacional de Segurança e Saúde do Trabalhador.

A questão central a ser enfrentada, entretanto, na travessia a ser percorrida em prol da saúde do trabalhador, é a construção de uma cultura que abarque os elementos aqui delineados, os quais dizem respeito à forma como se enfrentam determinadas mudanças sociais e às concepções de mundo e valores que são socialmente aceitas e transmitidas. Torna-se imprescindível estabelecer um conjunto de valores e condutas voltado para um processo educativo e participativo que contribua para o desenvolvimento individual e coletivo do ser humano, em que a saúde e o trabalhador sejam vistos na sua integralidade. Entende-se ser necessária, fundamentalmente, a construção de uma cultura capaz de integrar saberes, o que pressupõe a realização de ações interdisciplinares sem a supremacia de um determinado campo do conhecimento, uma vez que nenhuma área sozinha consegue dar conta das complexas relações e determinações que incidem sobre a saúde do trabalhador.

Assim, o estabelecimento de uma cultura voltada para a formação e o desenvolvimento humano requer organizações e sujeitos capazes de responder às mudanças em curso sem se omitir de seu papel neste processo e/ou aceitá-las como naturais ou inevitáveis. Requer, acima de tudo, a defesa intransigente de um projeto societário que enfrente as contradições presentes no processo de saúde e trabalho.

\section{Considerações para um debate continuado}

Tem-se presente que as formulações aqui apresentadas trazem em si elementos para uma reflexão inesgotável sobre a saúde e o trabalho na atualidade, constituindo-se em categorias que expressam a nova configuração societária, na qual o trabalho tem novos significados e determinações. A saúde, por sua vez, expressa a sinergia com as condições de vida e trabalho e só pode ser pensada na sua totalidade num cenário em que a dimensão social não seja ocultada por diferentes mecanismos presentes na sociedade.

Portanto, a dinâmica da produção, as condições de trabalho e o modo de vida continuam sendo fontes importantes para que se compreenda o processo de saúde, adoecimento e morte dos trabalhadores. 
Ao evidenciar o acidente de trabalho e as doenças profissionais como expressão e síntese do processo de saúde-doença e trabalho, torna-se constitutiva a busca de uma "contralógica" que trabalhe na perspectiva da saúde e segurança no trabalho como estratégia organizacional, fundada em processos participativos e educativos, nas diferentes instâncias de tomada de decisão. Esses modelos de gestão participativa, de mudanças nas condições físicas, ergonômicas e organizacionais, pactuações em torno de prioridades, estabelecimento de práticas inovadoras e relações horizontais têmse revelado importantes instrumentos para uma nova cultura em saúde e segurança no trabalho desde que não sejam utilizados como meros instrumentos de elevação das

\section{Referências}

ALBORNOZ, S. O que é trabalho? 6. ed. São Paulo: Brasiliense, 1994. (Coleção Primeiros Passos, 171).

BRASIL. Constituição da República Federativa do Brasil. Brasília, 1988.

. Lei $n^{\circ} 8.213$, de 24 de julho

de 1991 e Decreto $n^{\circ} 2.172$, de 05 de março de 1997. Dispõe sobre o Plano de Benefícios da Previdência Social. Brasília: Ministério da Previdência e Assistência Social, 1997.

. Ministério da Previdência Social. Anuário estatístico de acidentes de trabalho e doenças profissionais. Brasília: Ministério da Previdência Social, 2005. Disponível em: http://www. previdenciasocial.gov.br. Acesso em: dez. 2006.

Ministério da Saúde. Resoluções da $3^{a}$ Conferência Nacional da Saúde do Trabalhador. Disponível em: http://www. saude.gov.br. Acesso em: abr. 2006.

BUSS, P. M. Promoção da saúde e qualidade de vida. Ciênc. saúde coletiva, Rio de Janeiro, v. 5, n 1, p. 163178, 2000.

DEJOURS, C. A loucura do trabalho: estudo de psicopatologia do trabalho. São Paulo: Cortez/Oboré, 1988.

DIAS, E. C. Saúde do trabalhador. In: TODESCHINI, R. (Org.). Saúde, meio ambiente e condições de trabalho: conteúdos básicos para uma ação sindical. São Paulo: Fundacentro/CUT, 1996. taxas de lucro. Sem dúvida, não se trata de uma tarefa fácil para os profissionais que atuam na área, tendo em conta a dinâmica de organização e gestão do trabalho e o tensionamento presente neste contexto, fundamentalmente, pela secundarização do papel do trabalhador nessa dinâmica. Os avanços obtidos com a construção de um novo conceito de saúde do trabalhador, nas últimas décadas, precisam ser consolidados socialmente, o que passa pelo reconhecimento da centralidade do trabalhador nesse processo, pela compreensão e enfrentamento dos determinantes sociais, econômicos, políticos e culturais presentes na sociedade atual e, por conseguinte, na saúde do trabalhador.

DWYER, T. Life mand and death at work: industrial accidents as case of socially produced error. New York/London: Plenum, 1991.

LAURELL, A. C.; NORIEGA, M. Processo de produção e saúde. São Paulo: Hucitec, 1989.

LLORY, M. Acidentes industriais: o custo do silêncio - operadores privados da palavra e executivos que não podem ser encontrados. Tradução de Alda Porto. Rio de Janeiro: MultiMais/Funenseg, 1999.

MACHADO, J. M. H.; MINAYO-GOMEZ, C. Acidentes de trabalho: concepções e dados. In: MINAYO, M. C. S. (Org.). Os muitos brasis: saúde e população na década de 80. São Paulo/Rio de Janeiro: Hucitec/Abrasco, 1995.

MENDES, J. R. M. Acidente de trabalho. In: CATTANI, A. D. (Org.). Trabalho e tecnologia: dicionário crítico. Petrópolis/ Porto Alegre: Vozes/Editora da Universidade, 2002. . $O$ acidente e a morte no trabalho. Porto Alegre: EDIPUCRS, 2003.

MENDES, J. M. R.; OLIVEIRA, P. A. B. Medicina do trabalho: o desafio da integralidade na atenção à saúde. In: VIEIRA, S. I. V. (Coord.). Medicina básica do trabalho. Curitiba: Gênesis, 1995. v. 4.

MINAYO-GOMEZ, C.; THEDIM-COSTA, S. M. F. A construção do campo da saúde do trabalhador: percurso e dilemas. Cad. Saúde Pública, Rio de Janeiro, v. 13, supl. 2, 1997. 
OLIVEIRA, P. A. B. Ergonomia. In: CATTANI, A. D. (Org.). Trabalho e tecnologia: dicionário crítico. Petrópolis/ Porto Alegre: Vozes/Editora da Universidade, 2002.

PEZERAT, H. A defesa das vítimas do amianto: implicações políticas e significado. Paris: Andeva, 2000. (mimeo)

POSSAS, C. Saúde e trabalho: A crise da Previdência Social. São Paulo: Hucitec, 1989.

SANTOS, E. M. Frutos anônimos da exploração: o caso dos acidentes e intoxicação dos trabalhadores do abacaxi em Sapé, Paraíba. 1985. Dissertação (Mestrado em Saúde Pública) - Escola Nacional de Saúde Pública, Fundação Oswaldo Cruz, 1985.
SELIGMAN, E. Saúde mental e trabalho. In: TUNDIS, S. (Org.). Cidadania e loucura mental no Brasil. Petrópolis: Vozes, 1990.

THÉBÀUD-MONY, A. Santé, travail et précarization sociale en banlieue parisienne. Sociologie Santé, Paris, n. 16, p. 40-55, 1997.

VIEIRA, C. E. Cultura e formação humana no pensamento de Antonio Gramsci. Educ. Pesqui., São Paulo, v. 25, n. 1, 1999. Disponível em: http://www.scielo. br/scielo.

WÜNSCH, D. S. A construção da desproteção social no contexto históricocontemporâneo do trabalhador exposto ao amianto. 2005. Tese (Doutorado em Serviço Social) - Faculdade de Serviço Social, Pontifícia Universidade Católica do Rio Grande do Sul. 2005. 